\title{
THE ROLE OF PUBLIC INFRASTRUCTURE FOR FIRM LOCATION AND INTERNATIONAL OUTSOURCING
}

\author{
HARTMUT EGGER \\ JOSEF FALKINGER
}

CESIFo WORKING PAPER No. 970

CATEgory 7: TRAdE Policy

JUNE 2003

Presented at CESifo Area conference on Public Sector Economics, May 2003

An electronic version of the paper may be downloaded

- from the SSRN website:

www.SSRN.com

- from the CESifo website: www.CESifo.de 


\title{
THE ROLE OF PUBLIC INFRASTRUCTURE FOR FIRM LOCATION AND INTERNATIONAL OUTSOURCING
}

\begin{abstract}
This paper presents a model in which final goods producers outsource intermediate input production. Intermediate inputs are differentiated and their production can be located at home or abroad. The model is used to examine competitive location policy in a (two-country) free trade agreement $(F T A)$. It is shown that national public infrastructure investment has a positive effect on both the number of intermediate input producers and the return to the immobile factor in the home country. International outsourcing from home declines. Opposite effects are triggered in the partner country. In a welfare analysis we characterize national infrastructure policies that aim to maximize national income (net of tax costs) and compare the non-cooperative $F T A$-equilibrium with optimal policies from an integrated point of view. It is shown when coordination of competitive location policies is useful and when it is not.

Abstract
\end{abstract}

JEL Code: F12, F15, F42, H54.

Keywords: international outsourcing, firm location, public infrastructure, welfare effects.

Hartmut Egger
University of Zurich
Department of Economics
Zurichbergstrasse 14
CH-8032 Zurich
Switzerland
egger@wwi.unizh.ch

Hartmut Egger

Department of Economics

urichbergstrasse 14

CH-8032 Zurich

egger@wwi.unizh.ch 


\section{Introduction}

Location has become a key issue in the political debate on the macroeconomic consequences of the recent wave of globalization. In the past, production of manufacturing goods was to a large extent integrated within a single firm so that a location change was an exceptional phenomenon. It meant that a wide range of different production stages had to be shifted from one place to another. However, technical progress in recent years has tremendously changed the production process. Increased fragmentability and lower costs for service links make production and assembling of different parts of the value added chain at different locations feasible and profitable (see Jones, 2000; and Jones and Kierzkowski, 2001). Therefore, modern industrial production is characterized by a high degree of vertical fragmentation and international outsourcing. ${ }^{1}$ This implies that the optimal location is chosen for individual production stages, and specialized intermediate input producers make use of competitive location advantages all over the world. Despite this salient feature of reality, a macroeconomic model that accounts for the relationship between international outsourcing and the location of intermediate input suppliers is so far missing in the literature. To close this gap is the purpose of our paper. It provides a simultaneous explanation of the location of intermediate input suppliers, the volume of international outsourcing and the returns to immobile production factors as a function of the economic fundamentals and of national public infrastructure provision which is used as a mean of competitive location policy. ${ }^{2}$

The literature on international outsourcing has so far predominantly built on tradi-

\footnotetext{
${ }^{1}$ Hummels et al. (2001) find for a sample of 14 economies (10 OECD memebers and four emerging markets countries) that the vertical specialization (i.e., international outsourcing) share of exports grew by about 30\% over the period of 1970-1990 and that growth in vertical specialization accounted for 30\% of the growth in the overall export/GDP ratio. See also Feenstra (1998) and Feenstra and Hanson (2001) for a discussion on the relvance of vertical fragmentation and international outsourcing in modern industrial production.

$2 "$ A competitive location policy is a comprehensive policy ... that includes all aspects that define the attractiveness of a location." (Brakman et al., 2002, p. 2; in translation of Dutch Ministry of Economic Affairs, 1999, p. 114 f.)
} 
tional trade models of the Heckscher-Ohlin, Ricardo and Ricardo-Viner type. In these models, perfect competition characterizes final as well as intermediate goods markets so that the location of intermediate input producers is undetermined. See for instance Arndt, 1997; Deardorff, 2001; Egger, 2002; Egger and Falkinger, 2002; Jones, 2000; Jones and Kierzkowski, 2001. ${ }^{3}$ Recently, a few studies have addressed the relationship between industry structure and international outsourcing. However, they primarily focus on imperfect competition in the final goods market and do not deal with the location of intermediate input producers and its relation to international outsourcing decisions of final goods suppliers. See Burda and Dluhosch, 2001, 2002.

The literature on multinational firms includes locational aspects (see for instance Markusen, 2002; Markusen and Venables, 2000). However, this literature focuses on intra-firm trade, whereas in our analysis outsourced components are purchased through arm's length transactions in (imperfect) markets. ${ }^{4}$ Moreover, in the theory of multinational firms both the decision on setting up a production plant abroad and the decision on intra-firm trade are simultaneously made by a multinational's headquarters. In our analysis of international outsourcing the intermediate input suppliers decide on the location of intermediate goods production and the final goods producers decide on the volume of international outsourcing. Firm location also plays an important role in the literature on economic geography (see for instance Krugman, 1991; Baldwin and Krugman, 2002; Krugman and Venables, 1995). However, the focus again lies on final goods production. Vertical fragmentation and international outsourcing are not considered.

The idea that firms are located at some place implies that there are fixed costs which

\footnotetext{
${ }^{3}$ Kohler (2001) accounts for fixed network costs that are entailed by international outsourcing.

${ }^{4}$ Recently, several studies have analyzed a multinational's decision to enter a foreign market through foreign direct investment and subsidiary production or through international outsourcing and arm's length transaction. This decision is based on a trade off between higher production costs in the case of foreign direct investment and the costs that arise from contractual imperfections in the case of arm's length transactions. (See e.g. Grossman and Helpman, 2002a, 2002b; and Markusen, 2002.) Such a decision problem is not considered in our paper. We focus on market transactions. Bilateral relations based on contractual arrangements are not considered.
} 
are invested at a certain location and not at another. Therefore, we consider imperfect competition in the intermediate goods market. Imperfections in the final goods market are ignored. Moreover, our model emphasizes the importance of public infrastructure investment for a country's attractiveness as a location for intermediate input production. There is broad consensus among economists and politicians that public infrastructure investment is an important aspect of a competitive location policy. EU members, for example, agreed upon a benchmark method to determine the competitiveness of the EU economies. Among 54 indicators that are used for the assessment, social and economic infrastructure plays a prominent role (see Brakman et al., 2002). And the Portland Development Commission (2002) states that "an important role of government is to increase economic capacity by improving quality and efficiency of public infrastructure and utilities necessary to business operation" (p. 7). In the context of vertical fragmentation, governments can use public infrastructure provision as a policy instrument to attract a higher number of intermediate input producers and therefore to reduce the volume of a country's component imports from abroad.

We set up a general equilibrium model with one final good and differentiated intermediate inputs. Production in the final goods sector employs internationally immobile low-skilled labor for assembling the outsourced (differentiated) intermediate inputs. They are supplied under monopolistic competition. Final goods markets as well as factor markets are competitive. Intermediate input production makes use of internationally mobile capital. We assume that two small industrialized economies characterized by identical production technologies and equal endowments form a free trade agreement (FTA). Endowments consist of immobile labor and mobile capital that is owned by residents of the respective country. Intermediate input suppliers can decide about their location within the FTA, thereby taking into account the attractiveness of the two FTA member countries for intermediate input production. This attractiveness depends on the fixed costs requirements for setting up a firm. Governments can influence the location choice of intermediate input suppliers through national infrastructure policy. Higher public infrastructure investment reduces fixed costs to set up a plant in this economy and therefore raises 
the attractiveness of a country. (See for a similar assumption Bougheas et al., 2000.) ${ }^{5}$

After introducing the basic framework in Section 2 and solving the FTA-equilibrium in Section 3, Section 4 provides a comparative-static analysis about the effects of public infrastructure investment on firm location, international outsourcing and wages. In Section 5 we analyze the role of public infrastructure investment as a competitive location policy instrument that is financed by lump-sum taxes. In addition, we investigate the role of policy coordination. In Section 6 we discuss the robustness of our findings, some considerations on wage dispersion in the FTA and a different interpretation of our results. The last section concludes.

\section{Theoretical Framework}

We consider economies with a single final good $Y$ (the numéraire good) and two primary production factors: internationally immobile (low-skilled) labor $L$ and internationally mobile $K$, which may be interpreted as capital or know-how. Primary factors are not directly transformed into the final good, there is also intermediate goods production. Production of final output makes use of differentiated intermediate inputs $x_{i}$ and primary input $L$. The production of differentiated intermediate inputs is outsourced by the final goods producers and purchased through arm's length transactions from (anonymous) intermediate input suppliers. Low-skilled labor requirements $L$ may be associated with business service activities that are essential in the assembling process. The production technology for final output $Y$ is of a Cobb-Douglas type and given by

$$
Y=X^{\alpha} L^{1-\alpha}, \quad\left(X=\sum_{i} x_{i}^{\rho}\right)^{1 / \rho}, \rho>\alpha .
$$

Following Ethier (1982) we assume that the contribution of intermediate inputs $x_{i}$ can be aggregated by a CES-index. For the production of differentiated intermediate inputs

\footnotetext{
${ }^{5}$ Holtz-Eakin and Lovely (1996) use a more general approach that allows public infrastructure investment to affect both variable and fixed costs of intermediate input production. Other studies, like Bougheas et al. (1999), assume that public infrastructure investment reduces transport costs. Such an effect is not considered in our model.
} 
employment of $K$ is essential. For the purpose of simplicity and in order to keep the analysis tractable, we assume that the production of differentiated intermediate inputs

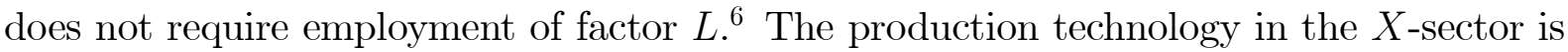
identical for all firms and given by

$$
x_{i}=K_{i}
$$

We follow the common approach that monopolistic competition characterizes the market for the differentiated intermediate inputs $x_{i}$. The number of intermediate inputs is determined by the zero-profit condition.

\section{Equilibrium under a Free Trade Agreement}

Let $H$ and $F$ be two industrialized economies characterized by identical production technologies and identical endowment $\bar{L}$ of the immobile factor. Moreover, an equal amount $\bar{K}$ units of the internationally mobile factor is owned by residents of $H$ and $F$, respectively. The two economies form a free trade agreement $(F T A)$ so that there are no tariff barriers on intermediate input and final goods trade between $H$ and $F$. In addition, we assume that commodity $Y$ is freely traded between the FTA and the rest of the world (RoW), whereas there is no trade of intermediate inputs outside the $F T A .^{7}$ Finally, we assume that both countries $H$ and $F$ are small economies. Then, perfect mobility of factor $K$ implies that its factor return, $r$, is determined in the world market outside the FTA. ${ }^{8}$ The

\footnotetext{
${ }^{6}$ See Ludema and Wooton (2000) for a similar assumption regarding the type of factor inputs in the production of sophisticated goods.

${ }^{7}$ There are several reasons why intermediate inputs cannot be traded between the FTA and the RoW. First, trading costs between the FTA and the RoW may be prohibitive for sophisticated intermediate inputs. Second, there may be a complex set of rules of origin, which prohibits use of intermediate inputs from outside the world. For a discussion on the negative effects of rules of origins in the presence of a FTA see Baldwin (2001) and Lloyd (2001). Finally, the RoW may employ an integrated production technology for commodity $Y$, so that there is neither supply of nor demand for sophisticated intermediate inputs in the RoW.

${ }^{8}$ This assumption reflects the idea that capital cannot be taxed by local governments given its high degree of international mobility.
} 
price, $w^{k}$, for the immobile factor depends on its location $k=H, F$. It is determined by the condition that labor earns its marginal product and full-employment $L=\bar{L}$ prevails in equilibrium. Thus, according to (1)

$$
\frac{(1-\alpha) Y^{k}}{\bar{L}}=w^{k}
$$

where $Y^{k}$ is the equilibrium level of final output in country $k=H, F$. Denote by $p_{H, i}^{k}$ $\left(p_{F, j}^{k}\right)$ the free on board (fob) prices of the intermediate component $x_{H, i}^{k}\left(x_{F, j}^{k}\right)$ produced by intermediate input supplier $i(j)$ located in country $H$ ( $F$, respectively) and used by a final goods producer located in market $k=H, F$. The free trade agreement allows the firms in the final goods sector to choose freely between intermediate inputs regardless of their origin. Optimal demand of $x_{H, i}^{k}\left(x_{F, j}^{k}\right)$ is determined by the first-order conditions for $\max _{x_{H, i}^{k}, x_{F, j}^{k}} Y-\left[\sum_{i} p_{H, i}^{k} x_{H, i}^{k}+\sum_{j} p_{F, j}^{k} x_{F, j}^{k}\right]-w_{k} \bar{L}$, which read:

$$
\begin{aligned}
& \frac{\alpha Y^{k}}{X^{k}}\left(\frac{X^{k}}{x_{H, i}^{k}}\right)^{1-\rho}=p_{H, i}^{k}, \quad i=1, \ldots, n_{H} ; k=H, F, \\
& \frac{\alpha Y^{k}}{X^{k}}\left(\frac{X^{k}}{x_{F, j}^{k}}\right)^{1-\rho}=p_{F, j}^{k}, \quad j=1, \ldots, n_{F} ; k=H, F,
\end{aligned}
$$

where $X^{k}:=\left[\sum_{i=1}^{n_{H}}\left(x_{H, i}^{k}\right)^{\rho}+\sum_{j=1}^{n_{F}}\left(x_{F, j}^{k}\right)^{\rho}\right]^{1 / \rho}$.

Using (4a), (4b) and defining aggregate price index $P_{X}^{k}:=\sum_{i=1}^{n_{H}}\left(p_{H, i}^{k}\right)^{1-\sigma}+\sum_{j=1}^{n_{F}}\left(p_{F, j}^{k}\right)^{1-\sigma}$, $\sigma=1 /(1-\rho)$, we find ${ }^{9}$ that $p_{H, i}^{k}=\left(\frac{\alpha Y^{k}}{P_{X}^{k}}\right)^{1-\rho}\left(x_{H, i}^{k}\right)^{-(1-\rho)}$ and $p_{F, j}^{k}=\left(\frac{\alpha Y^{k}}{P_{X}^{k}}\right)^{1-\rho}\left(x_{H, j}^{k}\right)^{-(1-\rho)}$, $k=H, F$, are the demand functions relevant for an $x_{i}$-producer located in country $H$ and an $x_{j}$-producer located in country $F$, respectively. This gives us for the maximization problem of an $x_{i}$-producer located in country $H$ :

$$
\max _{x_{H, i}^{H}, x_{H, i}^{F}}\left(x_{H, i}^{H}\right)^{\rho} D_{H}+\left(x_{H, i}^{F}\right)^{\rho} D_{F}-r\left(x_{H, i}^{H}+x_{H, i}^{F}\right)-t x_{H, i}^{F}-f_{H},
$$

where $D_{k}:=\left(\frac{\alpha Y^{k}}{P_{X}^{k}}\right)^{1-\rho}, k=H, F$, is exogenous to the single producer. Note that, according to (2), marginal production costs of intermediate goods are equal to factor price

\footnotetext{
${ }^{9}$ Use (4a), (4b) and the definition of $X^{k}$ to see that $\sum_{i=1}^{n_{H}} p_{H, i}^{k} x_{H, i}^{k}+\sum_{j=1}^{n_{F}} p_{F, j}^{k} x_{F, j}^{k}=\alpha Y^{k}$. Moreover, solve (4a) and (4b) for $x_{H, i}^{k}$ and $x_{F, j}^{k}$, respectively. Show then that $P_{X}^{k}=\left(\alpha Y^{k} / X^{k}\right)^{1-\sigma}$.
} 
$r$ of internationally mobile $K$ which is determined in the world market. $t>0$ are unit trade costs (but not tariffs) for international $x$-transactions, equivalent for both economies. $f_{k}$ are country-specific fixed costs. They depend on the country's infrastructure and reflect the attractiveness of a location for intermediate goods production and thus employment of $K$. The maximization problem of an $x_{j}$-producer located in country $F$ is:

$$
\max _{x_{F, j}^{F}, x_{F, j}^{H}}\left(x_{F, j}^{H}\right)^{\rho} D_{H}+\left(x_{F, j}^{F}\right)^{\rho} D_{F}-r\left(x_{F, j}^{H}+x_{F, j}^{F}\right)-t x_{F, j}^{H}-f_{F} .
$$

Within each market intermediate input producers are symmetric. Solving (5) and (6) we obtain a system of four first-order conditions for intermediate goods producers. Together with the two zero profit conditions of intermediate input producers and the six conditions in (3) and (4), describing the final goods sector in countries $H$ and $F$, we have twelve equations. They determine the twelve endogenous variables $x_{H}^{k}, x_{F}^{k}, p_{H}^{k}, p_{F}^{k}, n_{k}$, and $w^{k}, k=H, F$ as functions of the fundamentals of the two economies. In particular, the outcome depends on fixed costs $f_{k}$ which are affected by public infrastructure policy. This will allow us to do comparative-static analysis of policy effects (see Section 4). Equilibrium prices, quantities and numbers of intermediate input producers implied by (3)-(6) are given by the following expressions:

$$
\begin{gathered}
p_{k}^{k}=\frac{r}{\rho} \text { and } p_{k}^{k^{\prime}}=\frac{r+t}{\rho}, \\
x_{k^{\prime}}^{k}=x_{k}^{k}\left(\frac{r}{r+t}\right)^{\sigma} \text { and } x_{k}^{k}=\frac{\left[f_{k}-f_{k^{\prime}}\left(\frac{r}{r+t}\right)^{\sigma-1}\right] \phi}{1-\left(\frac{r}{r+t}\right)^{\sigma-1}\left(\frac{r}{r+t}\right)^{\sigma-1}}, \\
n_{k}=\frac{A\left[\left(1 / x_{k}^{k}\right)^{B}-\left(\frac{r}{r+t}\right)^{\sigma-1}\left(1 / x_{k^{\prime}}^{k^{\prime}}\right)^{B}\right]}{1-\left(\frac{r}{r+t}\right)^{\sigma-1}\left(\frac{r}{r+t}\right)^{\sigma-1}}
\end{gathered}
$$

with $k \neq k^{\prime} \in\{H, F\}$. Combining these equations with (1) and (3), we get equilibrium wages. Thereby, $\phi:=\frac{\rho}{(1-\rho) r}, A:=\left(\alpha^{\frac{1}{1-\alpha}} \bar{L}\right)^{B}\left(\frac{\rho}{r}\right)^{\frac{B}{1-\alpha}}$ and $B:=\frac{\rho(1-\alpha)}{\rho-\alpha}>1$ are constants depending on $r, \bar{L}$ and technology parameters. For a formal derivation see Appendix A.1.

The FTA-equilibrium was derived under the assumption of interior solutions (i.e., $\left.n_{k}>0, x_{H}^{k}>0, x_{F}^{k}>0, k=H, F\right)$. According to (8) and (9), the following conditions 
are necessary and sufficient for an interior solution

$$
t>r \cdot \max \left[1-\left(\frac{f_{H}}{f_{F}}\right)^{\frac{1}{\sigma-1}}, 1-\left(\frac{f_{F}}{f_{H}}\right)^{\frac{1}{\sigma-1}}\right]
$$

and

$$
1>\left(\frac{r}{r+t}\right)^{\sigma-1} \cdot \max \left[\left(\frac{x_{H}^{H}}{x_{F}^{F}}\right)^{B},\left(\frac{x_{F}^{F}}{x_{H}^{H}}\right)^{B}\right] .
$$

Roughly spoken, the two conditions are fulfilled if fixed costs $f_{H}$ and $f_{F}$ are not too different. In the symmetric case, i.e. if $f_{H}=f_{F}$, both conditions (10) and (11) are satisfied for any $t>0$.

\section{Public Infrastructure Expenditures, Firm Location, International Outsourcing and Wages}

In this section we provide a positive analysis on how public infrastructure expenditures affect the location of intermediate input producers, the amount of international outsourcing and wages in the two economies. As mentioned in the introduction we follow Bougheas et al. (2000) and assume that public infrastructure only has an impact on fixed costs $f_{k}$. An increase of public infrastructure investment in country $H$ reduces fixed costs $f_{H}$ and therefore increases the attractiveness of country $H$ as a location of intermediate input production. Fixed costs in country $F$ are not affected. ${ }^{10}$ Of course, there is an indirect effect of infrastructure expenditures on the productivity of final goods production, due to a change in number, size and location of intermediate input suppliers. ${ }^{11}$ This results in wage adjustments in the two economies, as will be explained in detail below.

We assume that there are two types of fixed costs: (i) fixed costs $f_{k}^{P}$ that are reduced/replaced by public infrastructure investment and (ii) firm-specific fixed costs $f_{k}^{0}$

\footnotetext{
${ }^{10}$ The results of our analysis are also obtained under sufficiently small spillover effects.

${ }^{11}$ Such an indirect effect is also emphasized in Holtz-Eakin and Lovely's (1996) analysis of the role of public infrastructure.
} 
that are independent of public infrastructure investment. ${ }^{12}$ Examples for the first type of fixed costs are connection facilities to outside world (e.g. internet). An example for the second type would be establishment of the intra-firm information and communication system. Formally, public infrastructure investment and fixed costs are related in the following way:

$$
f_{k}\left(G_{k}\right)=\left\{\begin{array}{ccc}
f_{k}^{0}+f_{k}^{P}\left(G_{k}\right) & \text { if } & G_{k} \in\left[0, G_{k}^{\max }[\right. \\
f_{k}^{0} & \text { if } & G_{k} \geq G_{k}^{\max }
\end{array}, k=H, F .\right.
$$

$G_{k}$ represents the quality of public infrastructure investment. $f_{k}^{P}\left(G_{k}\right)$ is a negatively sloped function in interval $G_{k} \in\left[0, G_{k}^{\max }\left[\right.\right.$, with $f_{k}^{P}(0)>0$ and $f_{k}^{P}\left(G_{k}^{\max }\right)=0$. The benefit from investment into public infrastructure reaches a maximum at $G_{k}=G_{k}^{\max }$. Public investment above this level cannot increase the attractiveness of a country for intermediate input production, since firm-specific fixed costs $f_{k}^{0}>0$ are independent of the quality of public infrastructure. It is assumed that $f_{k}^{0}$ and $f_{k}^{P}$ are restricted in such a way that (10) and (11) are satisfied for all possible combinations of $G_{k} \in\left[0, G_{k}^{\max }\right]$ and $G_{k^{\prime}} \in\left[0, G_{k^{\prime}}^{\max }\right]$ and interior solutions result with positive supply of intermediate inputs in both economies (i.e., $\left.n_{k}>0, x_{H}^{k}>0, x_{F}^{k}>0, k=H, F\right)$.

In the following comparative-static analysis, we consider variations of infrastructure parameter $G$ in country $H$ and hold fixed costs in country $F$ at $f_{F}^{1}=f_{F}\left(G_{F}\right)$ constant. Proposition 1 summarizes the effects of public infrastructure investment on number and location of intermediate input suppliers.

Proposition $1 A G_{H}$-induced decline of fixed costs $f_{H}$ has a positive effect on the number of intermediate input suppliers in country $H$ and a negative effect in country $F$. The impact on the total number of intermediate input suppliers is ambiguous. $f_{H}\left(G_{H}\right) \leq f_{F}^{1}$ guarantees a positive impact.

Proof. See Appendix A.2.

\footnotetext{
${ }^{12}$ In contrast to a pure subsidy for founding a new firm, infrastructure investment has a public good character.
} 
For any given $G_{H} \in\left[0, G_{H}^{\max }\left[\right.\right.$, an increase in infrastructure quality $G_{H}$ implies that fixed costs decline in country $H$ and $H$ becomes a more attractive location for intermediate input production. This has two effects. First, the $G_{H}$-induced decline of fixed costs in country $H$ leads ceteris paribus to entry of additional firms and therefore to a rise in the number of intermediate input suppliers located in country $H$. Second, for constant fixed costs in country $F$, there is also a shift of intermediate input producers from country $F$ to country $H$. As a consequence the number of intermediate input producers increases in country $H$ and declines in country $F$. The effect on the overall number of intermediate input producers is positive if fixed costs in country $H$ are not higher than in country $F$, but is ambiguous in general. If $f_{H}\left(G_{H}\right)>f_{F}^{1}$ a marginal decline of fixed costs in country $H$ induces a shift of firms from low-fixed costs country $F$ to high-fixed costs country $H$, which tends to lower the equilibrium number of firms. If this negative "shift effect" dominates the positive "new entry" effect, the total number of intermediate input producers declines in response to a $G_{H}$-induced reduction of fixed costs $f_{H}$.

Next we consider the impact of public infrastructure investment on international outsourcing from the two economies. We are interested in both the volume of international outsourcing, i.e. $n_{k^{\prime}} x_{k^{\prime}}^{k}, k \neq k^{\prime} \in\{H, F\}$, as well as the international outsourcing intensity $\xi_{k}:=\frac{n_{k^{\prime}} x_{k^{\prime}}^{k}}{n_{k} x_{k}^{k}}$, which is a measure for the openness of country $k$ with respect to intermediate goods imports. ${ }^{13}$ The impacts of public infrastructure investment on international outsourcing are summarized in Proposition 2.

Proposition $2 A G_{H}$-induced decline of fixed costs $f_{H}$ leads to a decline in the volume of country $H$ 's international outsourcing, i.e., a reduction of $n_{F} x_{F}^{H}$, and an increase in the volume of country $F$ 's international outsourcing, i.e., an increase of $n_{H} x_{H}^{F}$. The

\footnotetext{
${ }^{13}$ In the literature international outsourcing intensity is often measured as intermediate goods imports relative to gross production. However, a change in this measure comprises several effects, namely, (i) a change in the resource requirements per output, (ii) changes in overall (national and international) outsourcing, maybe due to technological changes in the final goods production, and (iii) variations in international relative to national outsourcing. Since we are interested in the foreign impact only, we think that $\xi_{k}=\frac{n_{k^{\prime}}}{n_{k}} \frac{x_{k^{\prime}}^{k}}{x_{k}^{k}}$ is the better measure.
} 
international outsourcing intensity decreases in country $H$ and increases in country $F$.

\section{Proof. See Appendix A.2.}

For any given $G_{H} \in\left[0, G_{H}^{\max }[\right.$, a higher quality of public infrastructure in country $H$ induces at the same time a rise in the number $n_{H}$ of intermediate good varieties produced in country $H$ and a decline in the number $n_{F}$ of varieties produced in $F$ (see Proposition 1). In addition, there is an output effect. Lower fixed costs in country $H$ makes firm entry easier. Thus, more varieties compete for use by the final goods producers. This drives down demand per intermediate component in country $H$, i.e., $x_{H}^{H}$ and $x_{F}^{H}$ decline. ${ }^{14}$ In sum, intermediate goods imports of country $H$, i.e., $n_{F} x_{F}^{H}$, are reduced. The opposite happens in country $F$, where the decline in the number of locally produced varieties leads to higher demand per intermediate input, i.e., both $x_{F}^{F}$ and $x_{H}^{F}$ increase, so that country $F$ 's international outsourcing $n_{H} x_{H}^{F}$ is stimulated.

For the international outsourcing intensity $\xi_{H}=\frac{n_{F} x_{F}^{H}}{n_{H} x_{H}^{H}}$ both overall local production $n_{H} x_{H}^{H}$ and overall import of intermediate inputs $n_{F} x_{F}^{H}$ are relevant. Whereas an increase in public infrastructure investment unambiguously leads to a reduction of intermediate goods imports $n_{F} x_{F}^{H}$, there are two opposing effects on the overall level of local production in country $H$. The number of varieties produced in country $H$ increases (Proposition 1), but output of an individual firm $\left(x_{H}^{H}\right)$ declines (see discussion above). As proved in the appendix, the first effect dominates and overall local production $n_{H} x_{H}^{H}$ turns out to be positively related to public infrastructure investments in country $H$. International outsourcing intensity $\xi_{H}$ therefore declines if the quality of public infrastructure in country $H$ is improved. That means, intermediate goods imports are replaced by local production in country $H$. The opposite finding holds for the international outsourcing intensity $\xi_{F}$.

Finally, policy is interested in the effects of infrastructure quality on wages. (Note that the earnings of capital owners are determined in the world market.) At this stage of our analysis we cannot address net wage effects, since the question of how public

\footnotetext{
${ }^{14}$ Note that, according to $(8), x_{H}^{H}$ and $x_{F}^{H}$ vary proportionally since relative prices are fixed by $t, r$ and $\rho$.
} 
infrastructure investment is financed has not been considered so far. The tax burden of public infrastructure investment is taken into account in Section 5.

According to (1) and (3), marginal productivity of $L$ and thus the wage rate depend on the CES-aggregator $X$ of intermediate components. As a consequence, wages critically depend on how many intermediate input suppliers are located in $H$ and $F$, respectively, and on the volume of intermediate inputs purchased from firms at the two locations. The following proposition summarizes the wage effects resulting when public infrastructure policy changes the attractiveness of location $H$.

Proposition $3 A G_{H}$-induced decline of fixed costs $f_{H}$ leads to higher wages in country $H$ and lower wages in country $F$.

\section{Proof. See Appendix A.2.}

A decline of fixed costs $f_{H}$ implies that the number of intermediate input suppliers in $H$ increases. This dominates the negative size effect so that total home production of intermediate good suppliers located in country $H$, i.e., $n_{H} x_{H}^{H}$, increases. At the same time, there is a negative effect on outsourcing to $F$ implying that $n_{F} x_{F}^{H}$ is reduced. We find that the positive effect on marginal labor productivity of the increase in homebased intermediate goods production $n_{H} x_{H}^{H}$ dominates the negative effect of the decline in $n_{F} x_{F}^{H}$. Thus, the return to immobile labor in country $H$ increases. The opposite holds for country $F$. In sum, we find that public infrastructure investment by increasing the attractiveness of a country as a location for intermediate input production reduces international outsourcing of that country and has a positive impact on wages. However, there are negative effects of public infrastructure investments in the partner country. These negative effects lead to a decline in the number of local intermediate input producers in country $F$, which cannot be offset by larger intermediate goods imports, so that wages in country $F$ are negatively affected by higher infrastructure investment in country $H$.

In Section 5 we extend the positive analysis presented in this section and investigate the role of public infrastructure expenditures as a policy strategy. Thereby, we assume that total income of residents, net of the tax burden of public infrastructure investment, 
is the objective of the government.

\section{Public Infrastructure Investment as a Competitive Location Policy}

By providing a certain level of infrastructure quality governments can influence the attractiveness of their country as a location for firms supplying intermediate inputs, the production of which is outsourced by the producers of final output. This affects the macroeconomic equilibrium, in particular the wage earned by immobile labor. Thus, the choice of public infrastructure quality $G_{k}$ is a policy instrument for maximizing the citizen's welfare. Welfare is given by national income net of tax payments for public infrastructure finance, i.e. by $^{15}$

$$
W^{k}=w^{k} \bar{L}+r \bar{K}-T^{k}, \quad k=H, F
$$

$T^{k}$ denotes lump-sum taxes which are used for financing public infrastructure quality $G_{k}$ in country $k$. Due to the symmetry of the two economies with respect to $\bar{L}, \bar{K}$ and $r$, differences in the welfare levels can only arise if wages $w^{k}$ and/or lump-sum taxes are different in $H$ and $F$. Both $w^{k}$ and $T^{k}$ depend on the chosen level $G_{k}$ of public infrastructure quality. It is assumed that providing level $G_{k}$ requires $\mu_{k} G_{k}$ units of final output. Formally, the production technology for public infrastructure is given by

$$
\mu_{k} G_{k}=Y^{k}, \quad k=H, F .
$$

$\mu_{k}>0$ is a cost parameter. The higher $\mu_{k}$, the more costly it is to provide $G_{k}$. Since $Y$ is the numéraire good, $T^{k}=\mu_{k} G_{k}$ gives the tax burden implied by public infrastructure quality $G_{k}$ in country $k$.

It is clear that the optimal infrastructure choice critically depends on the functional specification of $f_{k}^{P}(\cdot)$. For the sake of simplicity we assume that $f_{k}^{P}(\cdot)$ is a linear function

\footnotetext{
${ }^{15}$ Remember that there is only one consumption good, namely commodity $Y$, and that $r \bar{K}$ is capital income of residents of country $k$.
} 
in interval $\left[0, G_{k}^{\max }\right]$, given by $f_{k}^{P}\left(G_{k}\right)=\Psi^{k}-G_{k}, k=H, F$. (A discussion on the robustness of our results with respect to this specification is provided in Section 6.1.)

\subsection{The Optimal Level of Public Infrastructure Investment}

According to Proposition 3, wage $w^{k}$ is an increasing function of public infrastructure quality $G_{k}$. Let for a given level $G_{k^{\prime}}$ in the partner country $W_{0}^{k}\left(G_{k}, G_{k^{\prime}}\right):=w^{k} \bar{L}+r \bar{K}$, be the possible levels of gross national income in $k$. Straightforward calculations show that $W_{0}^{k}$ is an increasing and strictly convex function of $G_{k}$ in interval $\left[0, G_{k}^{\max }\right.$. Since $T^{k}$ is linear in $G_{k}$, there are only two candidates for an optimal $G_{k}$ decision, namely $G_{k}=0$ and $G_{k}=G_{k}^{\max }$. This can be seen in figure 1, where, for a given $G_{F}, W^{H}\left(G_{H}\right)=$ $W_{0}^{H}\left(G_{H}, G_{F}\right)-\mu_{H} G_{H}$ is drawn for two different cost coefficients $\mu_{H}^{1}>\mu_{H}^{2}$ of public infrastructure provision.

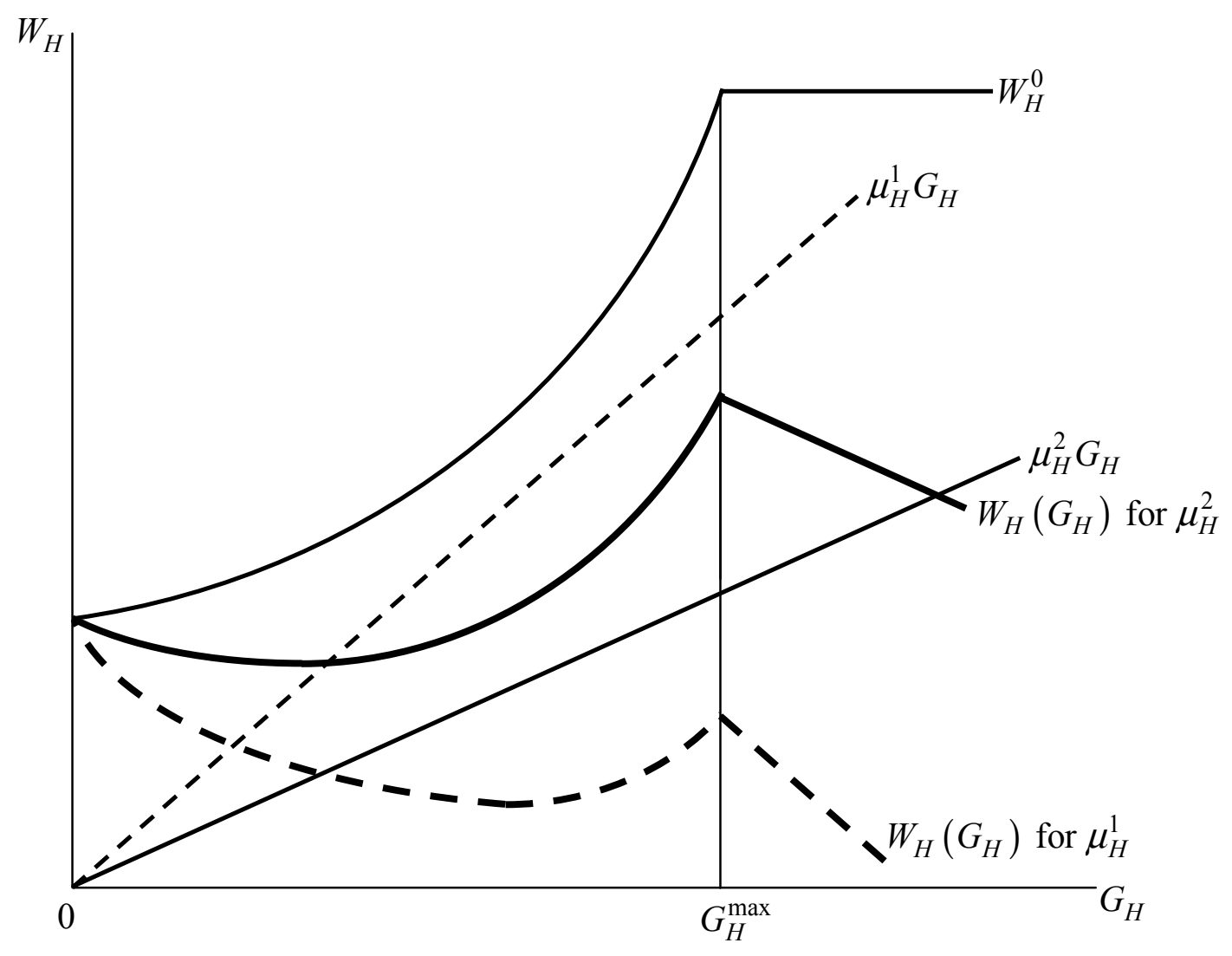

Figure 1: $W_{H}\left(G_{H}\right)$ for a given $G_{F}$ 
Since fixed costs of firms cannot be further reduced by increasing $G_{k}$ beyond ${ }^{16} G_{k}^{\max }$, gross income $W_{0}^{H}$ is independent of $G_{H}$ to the right of $G_{H}^{\max }$. However, welfare $W^{H}\left(G_{H}\right)$ declines due to the additional tax burden induced by higher public infrastructure expenditures. The dotted line $\mu_{H}^{1} G_{H}$ indicates a situation with low productivity in public infrastructure provision. In this case, the welfare maximizing $G_{H}$-decision (for a given level of public infrastructure in country $F$ ) is given by $G_{H}=0$ as can be seen from the dotted welfare function $W^{H}\left(G_{H}\right)$ for $\mu_{H}^{1}$. In contrast, if productivity in infrastructure provision is high, i.e. if $\mu_{H}$ is low, the welfare maximizing $G_{H^{-}}$decision is given by $G_{H}=G_{H}^{\max }$. This case is represented by the solid line $\mu_{H}^{2} G_{H}$ and solid welfare function $W^{H}\left(G_{H}\right)$ for $\mu_{H}^{2}$.

For any given level of public infrastructure quality $G_{k^{\prime}}$ in the partner country there is a threshold $\bar{\mu}_{k}\left(G_{k^{\prime}}\right)$ of the cost of infrastructure provision at which the government in country $k$ is indifferent between choosing $G_{k}=0$ or $G_{k}=G_{k}^{\max }$. This cost threshold is given by the condition $W^{k}(0)=W^{k}\left(G_{k}^{\max }\right)$ which is equivalent to $W_{0}^{k}\left(0, G_{k^{\prime}}\right)=$ $W_{0}^{k}\left(G_{k}^{\max }, G_{k^{\prime}}\right)-\mu_{k} G_{k}^{\max }$. Thus,

$$
\bar{\mu}_{k}\left(G_{k^{\prime}}\right):=\frac{w^{k}\left(G_{k}^{\max }, G_{k^{\prime}}\right)-w^{k}\left(0, G_{k^{\prime}}\right)}{G_{k}^{\max }} \bar{L},
$$

where $w^{k}\left(G_{k}, G_{k^{\prime}}\right)$ denotes the equilibrium wage in country $k$ when infrastructure quality is $G_{k}$ in country $k$ and $G_{k^{\prime}}$ in country $k^{\prime}$. Obviously, for a given level $G_{k^{\prime}}$ in the partner country $k^{\prime}$, the optimal choice for country $k$ is $G_{k}=G_{k}^{\max }$ if $\mu_{k}<\bar{\mu}_{k}\left(G_{k^{\prime}}\right)$ and $G_{k}=0$ if $\mu_{k}>\bar{\mu}_{k}\left(G_{k^{\prime}}\right)$, respectively. The infrastructure level $G_{k^{\prime}}$ in the partner country affects $w_{k}$, according to our analysis in Section 4 , and thus $\bar{\mu}_{k}\left(G_{k^{\prime}}\right)$, according to (15). Combining these facts, we obtain the following results concerning the optimal infrastructure policy of country $k$ in response to a given infrastructure policy of partner country $k^{\prime}$.

Proposition 4 Let $k, k^{\prime} \in\{H, F\}, k \neq k^{\prime}$. Then: $\bar{\mu}_{k}\left(G_{k^{\prime}}\right)$ is decreasing in $G_{k^{\prime}}$ and (i) if $\mu_{k} \leq \bar{\mu}_{k}\left(G_{k^{\prime}}^{\max }\right)$, then $G_{k}=G_{k}^{\max }$ is a dominant strategy; (ii) if $\mu_{k} \geq \bar{\mu}_{k}(0)$, then

\footnotetext{
${ }^{16}$ The remaining fixed costs are firm-specific, recall (12).
} 
$G_{k}=0$ is a dominant strategy; (iii) if $\left.\mu_{k} \in\right] \bar{\mu}_{k}\left(G_{k^{\prime}}^{\max }\right), \bar{\mu}_{k}(0)\left[\right.$, then $G_{k}=0$ is the optimal response to $G_{k^{\prime}}=G_{k^{\prime}}^{\max }$ and $G_{k}=G_{k}^{\max }$ is the optimal response to $G_{k^{\prime}}=0$.

\section{Proof. See Appendix A.2.}

The economic interpretation of Proposition 4 is straightforward. If a country's productivity in producing public infrastructure quality is high so that infrastructure can be improved at relatively low cost, then the country should provide top quality regardless of the situation in the partner country. In contrast, for a country with relatively high cost of infrastructure provision competitive location policy in form of infrastructure investment would be counterproductive from a welfare point of view. However, in intermediate cases - with a less extreme cost structure - optimal policy depends on the other country's position. For countries with intermediate costs of infrastructure our analysis suggests not to imitate the partner country. To the contrary, top infrastructure provision only pays if the other country has poor infrastructure quality.

These results are of particular interest in the context of the discussion about core and periphery economies. They show that public infrastructure investments can explain core-periphery patterns as politico-economic equilibria ${ }^{17}$ - with the core country being characterized by high infrastructure quality, a large number of intermediate input producers, low international outsourcing and high productivity of labor (and therefore high wages), whereas the opposite holds true in the periphery country characterized by low taxes and a low quality level of public infrastructure. While part (i) and part (ii) of Proposition 4 indicate that the differentiation into core and periphery is determined by differences in infrastructure costs, part (iii) of the proposition points out that a differentiation into core and periphery also can result without such differences. Even in the case of ex ante perfectly symmetric economies (i.e. $f_{H}^{0}=f_{F}^{0}, \Psi^{H}=\Psi^{F}, G_{H}^{\max }=G_{F}^{\max }$ and $\left.\mu_{H}=\mu_{F}\right)$, countries may ex post be different with respect to the optimally chosen quality level of public infrastructure $G_{k} \cdot{ }^{18}$

\footnotetext{
${ }^{17}$ In Krugman (1991) economies of scale, transport costs and the distribution of demand play an important role for the existence of a core-periphery structure.

${ }^{18}$ In this case, there exists a first-mover advantage for public infrastructure investment.
} 


\subsection{Welfare in the FTA: Is There a Need for Policy Coordina- tion?}

From the analysis in Section 4 we know that an infrastructure-induced welfare gain in country $H$ reduces wages and thus welfare in country $F$ (see Proposition 3). This negative effect on welfare in country $F$ is not considered by $H$ 's government when choosing the optimal level of public infrastructure investment. As a consequence uncoordinated infrastructure policies may lead to suboptimal FTA-welfare $W^{F T A}=W^{H}+W^{F}$. Consider the case of two symmetric countries. Then, national welfare net of taxes is given by $W^{k}=w^{k}\left(G_{k}, G_{k^{\prime}}\right) \bar{L}+r \bar{K}-\mu G_{k} \equiv W\left(G_{k}, G_{k^{\prime}}\right)$. Thus, the pay-off matrix for the two possible choices of optimal infrastructure policy $G_{k}=0$ and $G_{k}=G_{k}^{\max } \equiv \bar{G}$ is of the form

\begin{tabular}{|l|l|l|}
\cline { 2 - 3 } \multicolumn{1}{c|}{} & $G_{H}=0$ & $G_{H}=\bar{G}$ \\
\hline$G_{F}=0$ & $W(0,0) ; W(0,0)$ & $W(0, \bar{G}) ; W(\bar{G}, 0)$ \\
\hline$G_{F}=\bar{G}$ & $W(\bar{G}, 0) ; W(0, \bar{G})$ & $W(\bar{G}, \bar{G}) ; W(\bar{G}, \bar{G})$ \\
\hline
\end{tabular}

According to Proposition 4, three cases must be distinguished:

If cost $\mu$ is relatively low $G_{H}=\bar{G}$ and $G_{F}=\bar{G}$ are dominant strategies, i.e.

$$
W(\bar{G}, 0)>W(0,0) \text { and } W(\bar{G}, \bar{G})>W(0, \bar{G}) .
$$

Total welfare resulting in the non-cooperative equilibrium is thus

$$
W^{F T A}=2 W(\bar{G}, \bar{G})
$$

It is easy to check that (16) is consistent with $^{19} W(0,0)>W(\bar{G}, \bar{G})$ so that total welfare $W^{H}+W^{F}$ could be increased to $W^{F T A}=2 W(0,0)$ by cooperating at $G_{H}=G_{F}=$ $0 .{ }^{20}$ This does not mean that policy coordination at $G_{H}=G_{F}=0$ necessarily increases

\footnotetext{
${ }^{19}$ Note that Propositon 3 implies $W(\bar{G}, \bar{G})<W(\bar{G}, 0)$.

${ }^{20}$ Of course, the finding that zero public infrastructure expenditures are an efficient outcome should not be taken literally. Rather, the main result is that uncoordinated infrastructure policies can result in an overinvestment and therefore in a suboptimal level of $W^{F T A}$.
} 
welfare. For instance, if $\mu$ is sufficiently low, $G_{H}=G_{F}=\bar{G}$ is also optimal from the point of view of $F T A$-welfare. ${ }^{21}$

Under high infrastructure cost $\mu$, we have (from part (ii) of Proposition 4)

$$
W(0,0)>W(\bar{G}, 0) \text { and } W(0, \bar{G})>W(\bar{G}, \bar{G})
$$

and

$$
W^{F T A}=2 W(0,0)
$$

in the non-cooperative equilibrium. Since $W(0, \bar{G})<W(0,0)$ and $W(\bar{G}, \bar{G})<W(\bar{G}, 0)$, according to Proposition 3 and the definition of $W$, the two inequalities in (18) imply $W(\bar{G}, \bar{G})<W(0,0)$. Thus, in this case cooperation at $G_{H}=G_{F}=\bar{G}$ would definitely decrease welfare $W^{F T A}$ to $2 W(\bar{G}, \bar{G})<2 W(0,0)$.

In the case of intermediate cost levels $\mu$, we have

$$
W(\bar{G}, 0)>W(0,0) \text { and } W(0, \bar{G})>W(\bar{G}, \bar{G})
$$

and

$$
W^{F T A}=W(\bar{G}, 0)+W(0, \bar{G})
$$

in the non-cooperative equilibrium. It can be shown that (20) $\operatorname{implies}^{22} 2 W(\bar{G}, \bar{G})<$ $W(\bar{G}, 0)+W(0, \bar{G})$ but is consistent with $^{23} 2 W(0,0) \lessgtr W(\bar{G}, 0)+W(0, \bar{G})$. Thus, cooperation at $G_{H}=G_{F}=\bar{G}$ cannot improve $W^{F T A}$ but cooperation at $G_{H}=G_{F}=0$ may be beneficial.

In sum, sometimes though not always policy coordination can improve overall welfare compared to non-cooperative competitive location policy. In particular, an agreement to refrain from top infrastructure provision may be beneficial if infrastructure costs are high. Thus, contrary to models with international spillovers uncoordinated competitive policy may lead to "overtaxation" with regard to taxes that are raised to provide infrastructure for firms.

\footnotetext{
${ }^{21}$ In the case of $\mu_{k}=0$, such an outcome is guaranteed. See the discussion in Section 6.3.

${ }^{22}$ Proposition 3 implies $W(\bar{G}, \bar{G})<W(\bar{G}, 0)$. Moreover, according to (20), $W(\bar{G}, \bar{G})<W(0, \bar{G})$.

${ }^{23}$ On the one hand we have $W(0,0)<W(\bar{G}, 0)$ due to $(20)$, but on the other hand $W(0,0)>W(0, \bar{G})$, according to Proposition 3.
} 
Of course, even if $F T A$-welfare is maximized by uncoordinated public infrastructure decisions, there may be a need for (supranational) policy intervention in the form of redistributional measures. Without such an agreement, potential welfare losses arising from national competitive location policy may be a barrier to an FTA-formation, in particular in the case of intermediate costs of infrastructure. ${ }^{24}$

\section{Discussion}

The aim of this section is threefold. First, we investigate the robustness of our results under different specifications of $f_{k}^{P}\left(G_{k}\right)$. Second, we present some conclusions on how infrastructure policies affect wage dispersion in the FTA. Finally, we discuss in how far our findings would change if instead of infrastructure investment governments have a policy instrument which does not require public funding, say the "quality of economic and social order".

\subsection{Different Specifications for $f_{k}^{P}\left(G_{k}\right)$}

Under the linear specification $f_{k}^{P}\left(G_{k}\right)=\Psi^{k}-G_{k}$ used in Section 5 there are only two candidates for an optimal $G_{k}$ decision of national governments: The corner solutions $G_{k}=0$ and $G_{k}=G_{k}^{\max }$. This outcome critically depends on the convexity of gross national income $W_{0}^{k}$, as a function of $G_{k}$, in interval $\left[0, G_{k}^{\max }[\right.$. Therefore, the relevant question with respect to the robustness of our results is: In which way is the convexity of $W_{0}^{k}$ related to the properties of $f_{k}^{P}\left(G_{k}\right)$ ? It is straightforward to show that for any $G_{k^{\prime}}, W_{0}^{k}\left(G_{k}, G_{k^{\prime}}\right)$ is a convex function of $G_{k}$ as long as $f_{k}^{P}\left(G_{k}\right)$ is not "too convex" in interval $\left[0, G_{k}^{\max }\left[\right.\right.$. We know from Proposition 3 (proof) that $w^{k}=\frac{C\left(1 / x_{k}^{k}\right)^{\tilde{B}}}{\bar{L}}$, where $C, \widetilde{B}$ are constants determined by technical parameters and labor endowment. Thus,

\footnotetext{
${ }^{24}$ In the EU, structural funds at a supranational level help to overcome the infrastructure disadvantages of several countries and regions. See e.g. Breuss et al. (2001) for details on the agenda 2000's structural policy reform in the EU.
} 
$W_{0}^{k}=C\left(\frac{1}{x_{k}^{k}}\right)^{\widetilde{B}}+r \bar{K}$ and in view of (8)

$$
\frac{\partial^{2} W_{0}^{k}\left(G_{k}, G_{k^{\prime}}\right)}{\partial G_{k}^{2}} \gtreqless 0 \text { if } \frac{(\widetilde{B}+1) \phi}{1-\left(\frac{r}{r+t}\right)^{\sigma-1}\left(\frac{r}{r+t}\right)^{\sigma-1}} \frac{1}{x_{k}^{k}} \gtreqless \frac{d^{2} f_{k}^{P}\left(G_{k}\right) / d G_{k}^{2}}{\left[d f_{k}^{P}\left(G_{k}\right) / d G_{k}\right]^{2}} .
$$

According to $(22), W_{0}^{k}$ is, for any $G_{k^{\prime}}$, strictly convex in interval $\left[0, G_{k}^{\max }\right.$ [, if $f_{k}^{P}\left(G_{k}\right)$ is concave, i.e., if $d^{2} f_{k}^{P}\left(G_{k}\right) / d G_{k}^{2}<0$, or if it is a linear function as assumed in Section 5 . If the effect of public infrastructure $G_{k}$ on the fixed costs described by $f_{k}^{P}\left(G_{k}\right)$ follows a sufficiently convex shape, $W_{0}^{k}$ is concave in $G_{k}$. In this case the corner solutions $G_{k}=0$, $G_{k}=G_{k}^{\max }$ are still possible candidates for an optimal infrastructure policy if $\mu_{k}$ is either very high or very low, respectively. However, for intermediate values of infrastructure $\operatorname{cost} \mu_{k}$ the optimal infrastructure policy lies in the interior of interval $] 0, G_{k}^{\max }[$. Figure 2 illustrates, for a given level of $G_{F}$, the optimization problem of $H$ 's government when $W_{0}^{H}$ is concave.

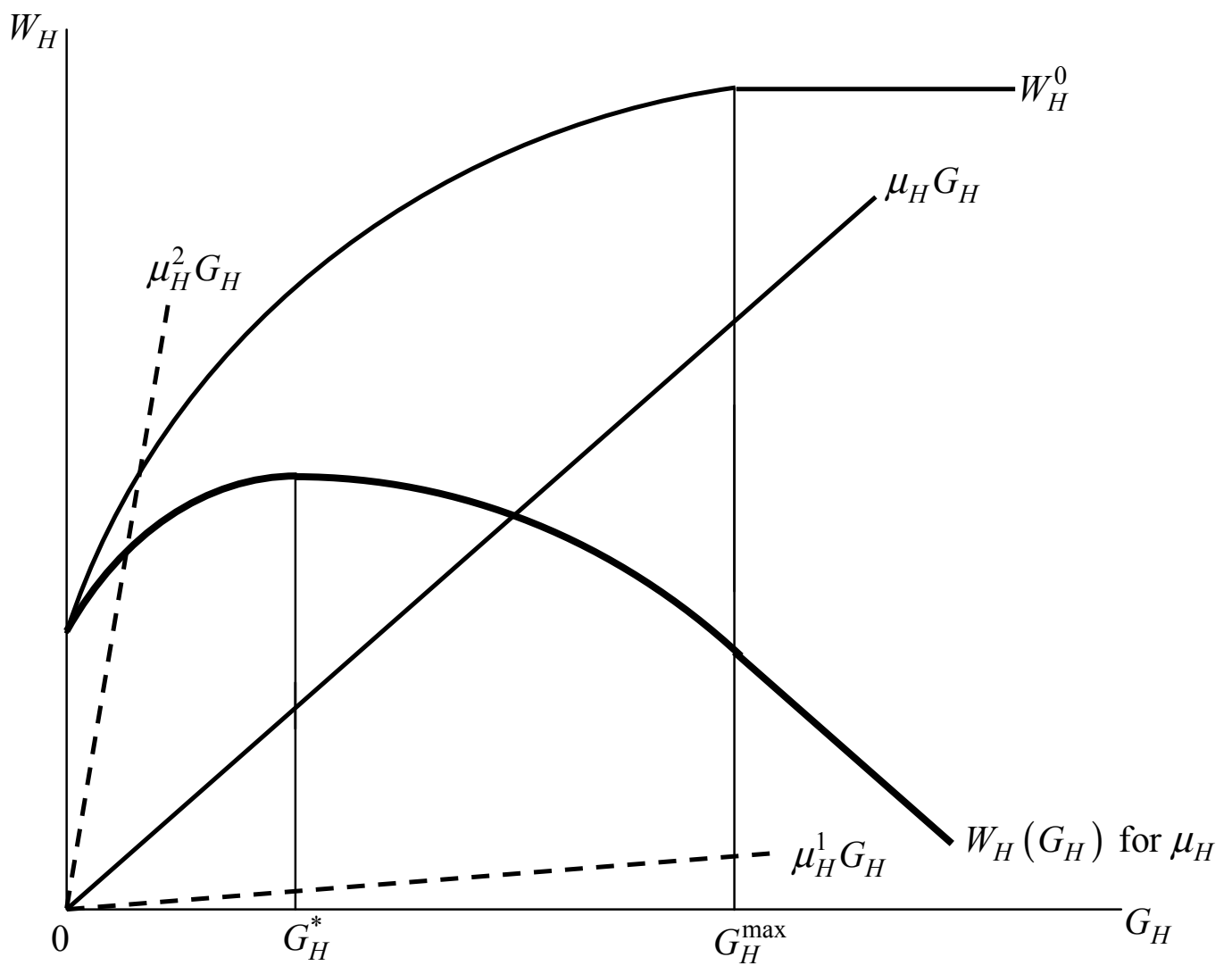

Figure 2: A concave $W_{0}^{H}\left(G_{H}\right)$-function 
$W_{0}^{H}$ and $\mu_{H} G_{H}$ represent gross national income and tax costs for infrastructure investments in country $H$. Welfare in $H$, represented by $W_{H}\left(G_{H}\right)$, reaches a maximum at $G_{H}^{*} \in\left[0, G_{H}^{\max }\left[. G_{H}=0 / G_{H}=G_{H}^{\max }\right.\right.$ would be the welfare-maximizing policy if tax costs were equal or higher than $\mu_{H}^{1} G_{H} /$ equal or lower than $\mu_{H}^{2} G_{H}$ (dotted lines), respectively.

\subsection{Public Infrastructure Investment and Wage Dispersion}

The impact of different policy measures on wage dispersion across economies has always been an important issue in the literature on international trade. Our analysis provides insights on how infrastructure policy affects wage dispersion in a FTA. Wage dispersion is measured by the ratio $w^{H} / w^{F}$. We consider a situation where firm-specific fixed costs are lower in country $H$ than in country $F$, i.e., $f_{H}^{0}<f_{F}^{0}$. This is the source of wage dispersion in the absence of public infrastructure investment. In all other respects the two countries are identical. In particular, $\mu_{k}=\mu$ and $f_{k}^{P}(\cdot)=\Psi-G_{k}, k=H, F$. Without public infrastructure wages are higher in country $H$ than in $F$ due to the differential in firm-specific fixed costs. This wage gap increases if both countries improve public infrastructure quality pari passu. ${ }^{25}$ The relationship between wage dispersion and variations in infrastructure quality $G_{H}=G_{F}=G$ is illustrated in figure 3. The intuition for this outcome is that the firm-specific fixed costs disadvantage of country $F$ gets a higher weight in the wage determination if public infrastructure investment reduces fixed $\operatorname{costs} f_{k}^{P}$.

\footnotetext{
${ }^{25}$ For a formal proof use $w^{k} / w^{k^{\prime}}=\left(x_{k^{\prime}}^{k^{\prime}} / x_{k}^{k}\right)^{\widetilde{B}}$, with $\widetilde{B}=\alpha\left(\frac{B}{\rho}-1\right)$, according to the proof of Proposition 3. In view of (8) we obtain $\frac{w^{k}}{w^{k^{\prime}}}=\left(\frac{f_{k^{\prime}}-f_{k}\left(\frac{r}{r+t}\right)^{\sigma-1}}{f_{k}-f_{k^{\prime}}\left(\frac{r}{r+t}\right)^{\sigma-1}}\right)^{\widetilde{B}}$, which can finally be transformed into

$$
\frac{w^{k}}{w^{k^{\prime}}}=\left(\frac{\left(f_{k^{\prime}}^{P}(G)+f_{k^{\prime}}^{0}\right)\left[1-\left(\frac{r}{r+t}\right)^{\sigma-1}\right]-\nu\left(\frac{r}{r+t}\right)^{\sigma-1}}{\left(f_{k^{\prime}}^{P}(G)+f_{k^{\prime}}^{0}\right)\left[1-\left(\frac{r}{r+t}\right)^{\sigma-1}\right]+\nu}\right)^{\widetilde{B}},
$$

where $f_{k}^{P}(G)=f_{k^{\prime}}^{P}(G)$ have been used and $\nu:=f_{k}^{0}-f_{k^{\prime}}^{0}$ denotes the firm-specific fixed costs differential between the two locations. From this we see immediately that $w^{k}>w^{k^{\prime}}$ if $\nu<0$. Moreover, in interval $G \in\left[0, G^{\max }\left[, \frac{d\left(w^{k} / w^{k^{\prime}}\right)}{d G}>0\right.\right.$ for $\nu<0$.
} 


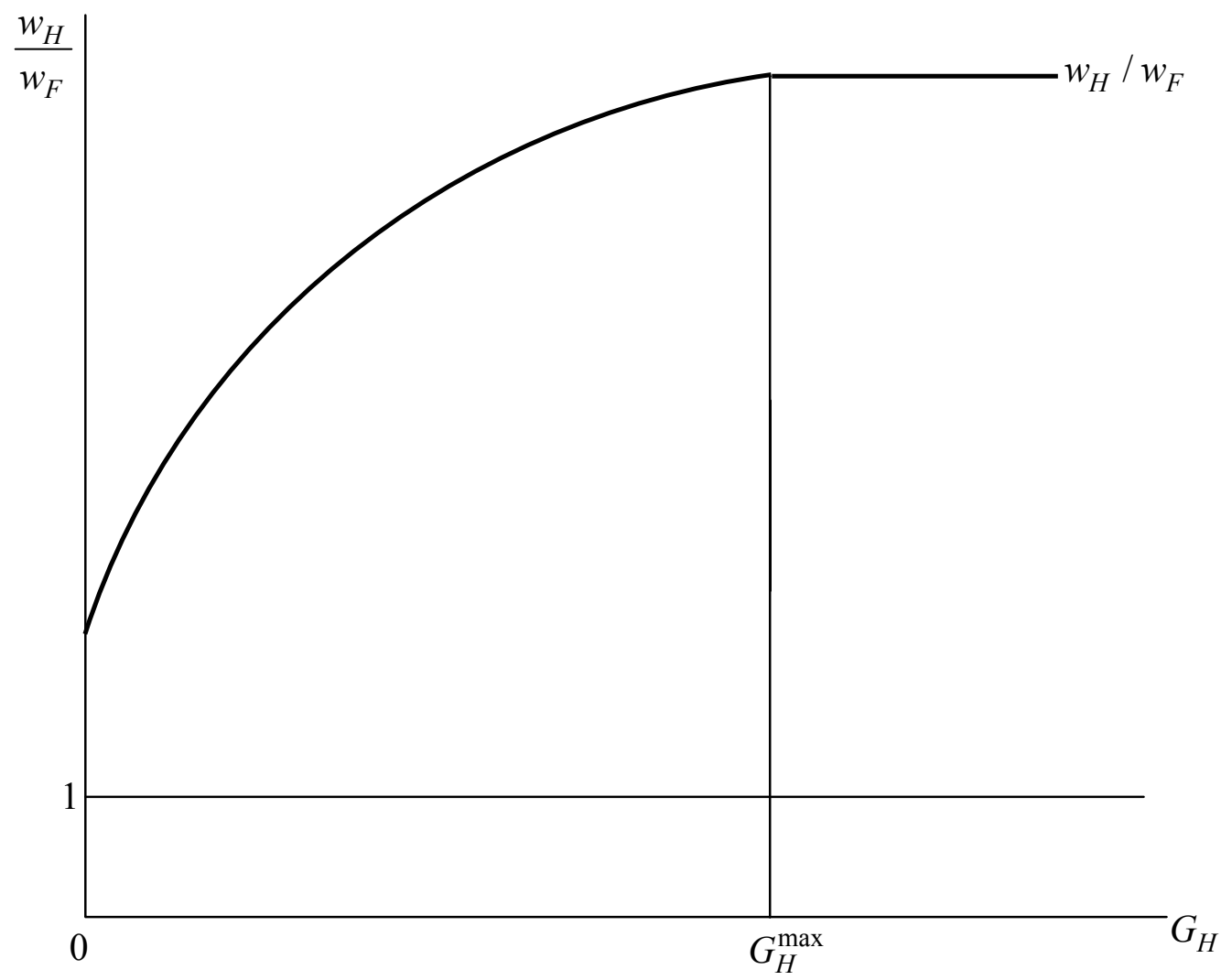

Figure 3: Public infrastructure investment and wage dispersion

Of course, this result does not mean that wage dispersion cannot be reduced through public infrastructure policies. But countries must coordinate at differentiated infrastructure policies. Suppose that the two countries considered above agree that wage dispersion is of common political concern. Then, lowering the wage dispersion requires policy coordination at $G_{H}<G_{F}$, which of course may be in conflict with the target of overall FT A-welfare maximization.

\subsection{The Quality of Economic and Social Order}

So far we have considered only one governmental instrument for a competitive location policy, namely public infrastructure investment. In the political discussion (especially in the context of international trade) the quality of economic and social order also plays an important role. Thereby, the term quality of economic order refers to a country's char- 
acteristics like market regulation, firm entry and investment rules, workplace protection, property rights legislation and so on. By social order we refer to respect of human rights, democratic support of government and other determinants of social stability. Both the economic and the social order are important factors for the decision on where to set up a firm. For example, in the absence of any property rights legislation, firms have to bear substantial (fixed) investment costs for security systems to protect their property rights. Social stability has comparable effects. The main difference to infrastructure investments is that there is no direct relationship between improvements in the quality of economic and social order and public funding. ${ }^{26}$ To make the two policy instruments comparable, we assume that the relationship between fixed costs and the quality of economic and social order can again be represented by (12). However, tax costs $T^{k}$ do not arise. This leaves the results in Section 4 unchanged. But choosing quality level $G_{k}^{\max }$ is now always a dominant strategy if $W_{0}^{k}$ is the objective function of the government. ${ }^{27}$ This is a direct consequence of Proposition 3. Since choosing top quality of economic and social order is a dominant strategy for national governments, our analysis does not indicate supranational agreements on property rights.

Although evident for national interest, income effects for the FTA are not a trivial result due to the negative effects of competitive location policy on the partner country. However, it can be shown that for any given quality level $G_{k^{\prime}}$ the $G_{k^{-}}$induced gain in country $k$ outweighs any losses in country $k^{\prime}$. In other words, FTA-income is maximized if both countries choose top quality of economic and social order. ${ }^{28}$ In sum, there is no

\footnotetext{
${ }^{26}$ To the extent that social stability requires redistributional measures with a deadweight loss, we are back in the previous case with positive costs $\mu_{k}$ of public funding $G_{k}$. Obviously, the same applies when establishment of economic order has costs.

${ }^{27}$ Due to zero tax costs, $W_{0}^{k}$ and $W^{k}$ coincide.

${ }^{28}$ To see this, use $W^{F T A}=C\left\{\left(\frac{1}{x_{H}^{H}}\right)^{\widetilde{B}}+\left(\frac{1}{x_{F}^{F}}\right)^{\widetilde{B}}\right\}+2 r \bar{K}$, where $C=(1-\alpha) \bar{L}^{1-\alpha} A^{\alpha / \rho}$ and $\widetilde{B}=$ $\alpha\left(\frac{B}{\rho}-1\right)$. After straightforward calculations one obtains

$$
\frac{d W^{F T A}}{d G_{k}}=-\frac{\widetilde{B} C \phi}{1-\left(\frac{r}{r+t}\right)^{\sigma-1}\left(\frac{r}{r+t}\right)^{\sigma-1}}\left\{\left(\frac{1}{x_{k}^{k}}\right)^{\widetilde{B}+1}-\left(\frac{r}{r+t}\right)^{\sigma-1}\left(\frac{1}{x_{k^{\prime}}^{k^{\prime}}}\right)^{\widetilde{B}+1}\right\} \frac{d f_{k}^{P}}{d G_{k}}
$$
}


need for policy coordination if the governments aim to improve the quality of economic and social order. However, redistributional measures may still be relevant in the case of asymmetric countries.

\section{Concluding Remarks}

In this paper we set up a model with one final good and differentiated intermediate inputs that are assembled by the use of immobile labor. We investigate how the location of intermediate input suppliers, international outsourcing and wages are affected by decisions on public infrastructure investment in two member countries of a FTA. We find that national public infrastructure investment, which reduces fixed costs for intermediate input production, raises the number of intermediate input suppliers, reduces international outsourcing activities of final goods producers and leads to higher wages in the home country. The opposite holds in the partner country, where the number of produced varieties as well as the return to the immobile factor decline, whereas international outsourcing is stimulated.

In a second step we investigate the role of public infrastructure investment as a competitive location policy of national governments which aim to maximize gross national income minus (lump-sum) tax payments. Since governments do not take into account the negative effects on the FTA partner country, policy coordination may result in a higher overall FTA-welfare level. Moreover, distributional conflicts may arise even in ex ante symmetric countries. Such conflicts may be an important impediment to a FTA-formation if no redistributional measures are considered.

With respect to the question of wage dispersion in the FTA, we find that wage dispersion arising from differences in firm-specific fixed costs increases if countries increase public infrastructure quality pari passu. In other words, the goal to lower wage gaps across countries requires coordination on different infrastructure policies. In a final step,

Note that $\widetilde{B}+1=B$, according to the definition of $B$. Then, $d W^{F T A} / d G_{k}>0$ directly follows from (9), (11) and $d f_{k}^{P} / d G_{k}<0$. 
we compare public infrastructure investment with variations in the quality of economic and social order that defines a country's attractiveness for intermediate input production as a function of property rights legislation, social stability and so on. Since changes in the quality of economic and social order are not directly related to tax costs, improving this quality is good for both national and FTA-income.

\section{Appendix}

\section{Appendix A.1: Derivation of Equilibrium Prices, Quantities and Firm Numbers}

The first-order conditions for (5) and (6) give us $x_{k}^{k}=\left(\rho D_{k} / r\right)^{\sigma}, x_{k}^{k^{\prime}}=\left(\rho D_{k^{\prime}} /(r+t)\right)^{\sigma}$ and thus

$$
x_{k^{\prime}}^{k}=x_{k}^{k}\left(\frac{r}{r+t}\right)^{\sigma}
$$

with $k \neq k^{\prime} \in\{H, F\}$. Because of iso-elastic demand, equilibrium prices are given by

$$
p_{k}^{k}=\frac{r}{\rho} \quad \text { and } \quad p_{k}^{k^{\prime}}=\frac{r+t}{\rho}
$$

This implies

$$
p_{k}^{k^{\prime}}=p_{k}^{k} \frac{r+t}{r}
$$

Profits of a firm in $k$ are given by

$$
\pi_{k}=\left(p_{k}^{k}-r\right) x_{k}^{k}+\left(p_{k}^{k^{\prime}}-r-t\right) x_{k}^{k^{\prime}}-f_{k}
$$

so that in view of (A.1) the zero-profit condition reduces to

$$
x_{k}^{k}=a_{k}-b x_{k^{\prime}}^{k^{\prime}}
$$

with $a_{k}:=\frac{f_{k}}{p_{k}^{k}-r}=\frac{\rho f_{k}}{(1-\rho) r}\left(\right.$ use (A.2)) and $b:=\frac{p_{k}^{k^{\prime}}-r-t}{p_{k}^{k}-r}\left(\frac{r}{r+t}\right)^{\sigma}=\left(\frac{r}{r+t}\right)^{\sigma-1}$ (use again (A.2)).

In an analogous way,

$$
x_{k^{\prime}}^{k^{\prime}}=a_{k^{\prime}}-b x_{k}^{k}
$$


with $a_{k^{\prime}}:=a_{k} \frac{f_{k^{\prime}}}{f_{k}}$. Solving the system of equations given by (A.5) and (A.6), we get

$$
x_{k}^{k}=\frac{a_{k}-a_{k^{\prime}} b}{1-b^{2}}=\frac{\left[f_{k}-f_{k^{\prime}}\left(\frac{r}{r+t}\right)^{\sigma-1}\right] \phi}{1-\left(\frac{r}{r+t}\right)^{\sigma-1}\left(\frac{r}{r+t}\right)^{\sigma-1}},
$$

with $\phi:=\frac{\rho}{(1-\rho) r}$ and $k \neq k^{\prime} \in\{H, F\}$.

Next, we derive the equilibrium number of firms. Since firms within countries are symmetric we have $X^{k}=\left[n_{k}\left(x_{k}^{k}\right)^{\rho}+n_{k^{\prime}}\left(x_{k^{\prime}}^{k}\right)^{\rho}\right]^{1 / \rho}$, with $k \neq k^{\prime} \in\{H, F\}$. In view of (A.1) this reduces to

$$
X^{k}=x_{k}^{k}\left[n_{k}+n_{k^{\prime}}\left(\frac{r}{r+t}\right)^{\frac{\rho}{1-\rho}}\right]^{1 / \rho} .
$$

Moreover, using (A.2) and the definition of $P_{X}^{k}$ we get

$$
P_{X}^{k}=\left(\frac{r}{\rho}\right)^{1-\sigma}\left[n_{k}+n_{k^{\prime}}\left(\frac{r+t}{r}\right)^{1-\sigma}\right] .
$$

Since $1-\sigma=-\frac{\rho}{1-\rho}$ we conclude from this

$$
X^{k}=x_{k}^{k}\left(P_{X}^{k}\right)^{\frac{1}{\rho}}\left(\frac{r}{\rho}\right)^{\frac{1}{1-\rho}} .
$$

Using (A.2) in demand function $x_{k}^{k}=\left(p_{k}^{k}\right)^{-\frac{1}{1-\rho}} \frac{\alpha Y^{k}}{P_{X}^{k}}$, we get $x_{k}^{k}=\left(\frac{r}{\rho}\right)^{-\sigma} \alpha Y^{k} / P_{X}^{k}$ which in view of $Y^{k}=\left(X^{k}\right)^{\alpha} \bar{L}^{1-\alpha}$ and (A.10) reduces to

$$
x_{k}^{k}=\alpha^{\frac{1}{1-\alpha}} \bar{L}\left(\frac{r}{\rho}\right)^{-\frac{1}{1-\rho}}\left(P_{X}^{k}\right)^{\frac{\alpha-\rho}{\rho(1-\alpha)}} .
$$

In view of (A.9) this can be rewritten as

$$
x_{k}^{k}=\left(\frac{r}{\rho}\right)^{-\frac{1}{(1-\alpha)}}\left(N_{k}\right)^{\frac{\alpha-\rho}{\rho(1-\alpha)}} \alpha^{\frac{1}{1-\alpha}} \bar{L},
$$

with $N_{k}:=n_{k}+n_{k^{\prime}}\left(\frac{r}{r+t}\right)^{\sigma-1}$. An analogous expression holds for $x_{k^{\prime}}^{k^{\prime}}$. After straightforward transformations, (A.12) can be rewritten as

$$
n_{k}+n_{k^{\prime}}\left(\frac{r}{r+t}\right)^{\sigma-1}=A\left(1 / x_{k}^{k}\right)^{B}
$$

and in a similar way we obtain

$$
n_{k^{\prime}}+n_{k}\left(\frac{r}{r+t}\right)^{\sigma-1}=A\left(1 / x_{k^{\prime}}^{k^{\prime}}\right)^{B},
$$


with $k \neq k^{\prime} \in\{H, F\} . B=\frac{\rho(1-\alpha)}{\rho-\alpha}$ and $A=\left(\alpha^{\frac{1}{1-\alpha}} \bar{L}\right)^{B}\left(\frac{\rho}{r}\right)^{\frac{B}{1-\alpha}}$ have been used.

and (A.14) give us (9).

\section{Appendix A.2: Proof of Propositions 1-3}

In the following derivations, fixed costs in country $F$ are given by $f_{F}^{1}$ and $G_{H} \in\left[0, G_{H}^{\max }[\right.$ holds.

\section{Proof of Proposition 1}

Use (8), (9) and (12) to find

$$
\frac{d n_{H}}{d G_{H}}=-\frac{A B \phi\left\{\left(\frac{1}{x_{H}^{H}}\right)^{B+1}+\left(\frac{r}{r+t}\right)^{\sigma-1}\left(\frac{r}{r+t}\right)^{\sigma-1}\left(\frac{1}{x_{F}^{F}}\right)^{B+1}\right\}}{\left[1-\left(\frac{r}{r+t}\right)^{\sigma-1}\left(\frac{r}{r+t}\right)^{\sigma-1}\right]^{2}} \frac{d f_{H}^{P}}{d G_{H}}>0
$$

and

$$
\frac{d n_{F}}{d G_{H}}=\frac{A B \phi\left\{\left(\frac{r}{r+t}\right)^{\sigma-1}\left(\frac{1}{x_{H}^{H}}\right)^{B+1}+\left(\frac{r}{r+t}\right)^{\sigma-1}\left(\frac{1}{x_{F}^{F}}\right)^{B+1}\right\}}{\left[1-\left(\frac{r}{r+t}\right)^{\sigma-1}\left(\frac{r}{r+t}\right)^{\sigma-1}\right]^{2}} \frac{d f_{H}^{P}}{d G_{H}}<0 .
$$

Moreover,

$$
\frac{d\left(n_{H}+n_{F}\right)}{d G_{H}}=-\frac{A B \phi\left[1-\left(\frac{r}{r+t}\right)^{\sigma-1}\right]\left\{\left(\frac{1}{x_{H}^{H}}\right)^{B+1}-\left(\frac{r}{r+t}\right)^{\sigma-1}\left(\frac{1}{x_{F}^{F}}\right)^{B+1}\right\}}{\left[1-\left(\frac{r}{r+t}\right)^{\sigma-1}\left(\frac{r}{r+t}\right)^{\sigma-1}\right]^{2}} \frac{d f_{H}^{P}}{d G_{H}} .
$$

Since $d f_{H}^{P} / d G_{H}<0, \frac{d\left(n_{H}+n_{F}\right)}{d G_{H}} \gtreqless 0$ if and only if $\left(\frac{x_{F}^{F}}{x_{H}^{H}}\right)^{B+1} \gtreqless\left(\frac{r}{r+t}\right)^{\sigma-1}$. According to (11) $\left(\frac{x_{F}^{F}}{x_{H}^{H}}\right)^{B}>\left(\frac{r}{r+t}\right)^{\sigma-1}$. However, this is only sufficient for $\left(\frac{x_{F}^{F}}{x_{H}^{H}}\right)^{B+1}>\left(\frac{r}{r+t}\right)^{\sigma-1}$ if $x_{F}^{F} \geq x_{H}^{H}$, i.e., according to (8), if $f_{F} \geq f_{H}$. Thus, $\frac{d\left(n_{H}+n_{F}\right)}{d G_{H}}>0$ if $f_{H}\left(G_{H}\right) \leq f_{F}^{1}$ and ambiguous otherwise.

\section{Proof of Proposition 2}

Step 1: Public infrastructure investment and the volume of international outsourcing: 
Use (8) and (12) to obtain $\frac{d x_{H}^{H}}{d G_{H}}=\frac{d f_{H}^{P} / d G_{H}}{1-\left(\frac{r}{r+t}\right)^{\sigma}\left(\frac{r}{r+t}\right)^{\sigma-1}}<0$ and $\frac{d x_{H}^{F}}{d G_{H}}=-\left(\frac{r}{r+t}\right)^{\sigma}\left(\frac{r}{r+t}\right)^{\sigma-1} \frac{d x_{H}^{H}}{d G_{H}}$. Then, $\frac{d\left(n_{H} x_{H}^{F}\right)}{d G_{H}}=\frac{d n_{H}}{d G_{H}} x_{H}^{F}+n_{H} \frac{d x_{H}^{F}}{d G_{H}}>0$ directly follows from (A.15). In a similar way use (A.16) and $\frac{d x_{F}^{H}}{d G_{H}}=\left(\frac{r}{r+t}\right)^{\sigma} \frac{d x_{H}^{H}}{d G_{H}}<0$ to find $\frac{d\left(n_{F} x_{F}^{H}\right)}{d G_{H}}=\frac{d n_{F}}{d G_{H}} x_{F}^{H}+n_{F} \frac{d x_{F}^{H}}{d G_{H}}<0$.

Step 2: Public infrastructure investment and the international outsourcing intensity:

According to (A.15)

$$
\frac{d n_{H}}{d G_{H}} x_{H}^{H}=-\frac{A B \phi\left[\left(\frac{1}{x_{H}^{H}}\right)^{B}+\left(\frac{r}{r+t}\right)^{\sigma-1}\left(\frac{r}{r+t}\right)^{\sigma-1}\left(\frac{1}{x_{F}^{F}}\right)^{B}\left(\frac{x_{H}^{H}}{x_{F}^{F}}\right)\right]}{\left[1-\left(\frac{r}{r+t}\right)^{\sigma-1}\left(\frac{r}{r+t}\right)^{\sigma-1}\right]^{2}} \frac{d f_{H}^{P}}{d G_{H}},
$$

and in view of (8) and (9)

$$
n_{H} \frac{d x_{H}^{H}}{d G_{H}}=\frac{A \phi\left[\left(\frac{1}{x_{H}^{H}}\right)^{B}-\left(\frac{r}{r+t}\right)^{\sigma-1}\left(\frac{1}{x_{F}^{F}}\right)^{B}\right]}{\left[1-\left(\frac{r}{r+t}\right)^{\sigma-1}\left(\frac{r}{r+t}\right)^{\sigma-1}\right]^{2}} \frac{d f_{H}^{P}}{d G_{H}} .
$$

This gives us by straightforward calculations

$$
\frac{d\left(n_{H} x_{H}^{H}\right)}{d G_{H}}=-\frac{A \phi\left[(B-1)\left(\frac{1}{x_{H}^{H}}\right)^{B}+E_{1}\left(\frac{1}{x_{F}^{F}}\right)^{B}\right]}{\left[1-\left(\frac{r}{r+t}\right)^{\sigma-1}\left(\frac{r}{r+t}\right)^{\sigma-1}\right]^{2}} \frac{d f_{H}^{P}}{d G_{H}}
$$

with $E_{1}:=\left(\frac{r}{r+t}\right)^{\sigma-1}\left[B\left(\frac{r}{r+t}\right)^{\sigma-1}\left(\frac{x_{H}^{H}}{x_{F}^{F}}\right)+1\right]$. Due to $\frac{d f_{H}^{P}}{d G_{H}}<0, \frac{d\left(n_{H} x_{H}^{H}\right)}{d G_{H}}>0$. Combining this with $\frac{d\left(n_{F} x_{F}^{H}\right)}{d G_{H}}<0$ (see step 1), we have $\frac{d \xi_{H}}{d G_{H}}<0$, where $\xi_{H}=\frac{n_{F} x_{F}^{H}}{n_{H} x_{H}^{H}}$ has been used.

In an analogous way, use

$$
\frac{d n_{F}}{d G_{H}} x_{F}^{F}=\frac{A B \phi\left[\left(\frac{r}{r+t}\right)^{\sigma-1}\left(\frac{1}{x_{H}^{H}}\right)^{B}\left(\frac{x_{H}^{H}}{x_{F}^{F}}\right)+\left(\frac{r}{r+t}\right)^{\sigma-1}\left(\frac{1}{x_{F}^{F}}\right)^{B}\right]}{\left[1-\left(\frac{r}{r+t}\right)^{\sigma-1}\left(\frac{r}{r+t}\right)^{\sigma-1}\right]^{2}} \frac{d f_{H}^{P}}{d G_{H}}
$$

according to (A.16) and

$$
n_{F} \frac{d x_{F}^{F}}{d G_{H}}=-\frac{A \phi\left[\left(\frac{r}{r+t}\right)^{\sigma-1}\left(\frac{1}{x_{F}^{F}}\right)^{B}-\left(\frac{r}{r+t}\right)^{\sigma-1}\left(\frac{r}{r+t}\right)^{\sigma-1}\left(\frac{1}{x_{H}^{H}}\right)^{B}\right]}{\left[1-\left(\frac{r}{r+t}\right)^{\sigma-1}\left(\frac{r}{r+t}\right)^{\sigma-1}\right]^{2}} \frac{d f_{H}^{P}}{d G_{H}}
$$

to obtain

$$
\frac{d\left(n_{F} x_{F}^{F}\right)}{d G_{H}}=\frac{A \phi\left(\frac{r}{r+t}\right)^{\sigma-1}\left[(B-1)\left(\frac{1}{x_{F}^{F}}\right)^{B}+E_{2}\left(\frac{1}{x_{H}^{H}}\right)^{B}\right]}{\left[1-\left(\frac{r}{r+t}\right)^{\sigma-1}\left(\frac{r}{r+t}\right)^{\sigma-1}\right]^{2}} \frac{d f_{H}^{P}}{d G_{H}}<0
$$


with $E_{2}:=B\left(\frac{x_{H}^{H}}{x_{F}^{F}}\right)+\left(\frac{r}{r+t}\right)^{\sigma-1}$. Together with $\frac{d\left(n_{H} x_{H}^{F}\right)}{d G_{H}}>0$, this implies $\frac{d \xi_{F}}{d G_{H}}>0$.

\section{Proof of Proposition 3}

According to (3), wages are given by the equation $w_{k}=\frac{(1-\alpha) Y^{k}}{\bar{L}}$, where $Y^{k}=\left(X^{k}\right)^{\alpha} \bar{L}^{1-\alpha}$, according to (1). Use $X^{k}=x_{k}^{k}\left[n_{k}+n_{k^{\prime}}\left(\frac{r}{r+t}\right)^{\sigma-1}\right]^{1 / \rho}, k \neq k^{\prime} \in\{H, F\}$, and $n_{k}+$ $n_{k^{\prime}}\left(\frac{r}{r+t}\right)=A\left(\frac{1}{x_{k}^{k}}\right)^{B}$, according to (A.13), to obtain $X^{k}=A^{1 / \rho}\left(\frac{1}{x_{k}^{k}}\right)^{\widetilde{B} / \alpha}$, where $\widetilde{B}:=$ $\alpha\left(\frac{B}{\rho}-1\right)>0$. Combine this with the fact that $\frac{d x_{H}^{H}}{d G_{H}}<0$ and $\frac{d x_{F}^{F}}{d G_{H}}>0$, according to (8) and (12), to establish $\frac{d w^{H}}{d G_{H}}>0$ and $\frac{d w^{F}}{d G_{H}}<0$.

\section{Proof of Proposition 4}

Assume $f_{k}^{P}\left(G_{k}\right)=\Psi^{k}-G_{k}, k=H, F$. Using (8), (12) and (15), we find for all $G_{k^{\prime}} \in$ $\left[0, G_{k^{\prime}}^{\max }\left[, k \neq k^{\prime} \in\{H, F\}\right.\right.$

$$
\frac{d \bar{\mu}\left(G_{k^{\prime}}\right)}{d G_{k^{\prime}}}=-\frac{\widetilde{B} C \phi\left(\frac{r}{r+t}\right)^{\sigma-1}\left[\left.\left(\frac{1}{x_{k}^{k}}\right)^{\widetilde{B}+1}\right|_{G_{k}=G_{k}^{\max }}-\left.\left(\frac{1}{x_{k}^{k}}\right)^{\widetilde{B}+1}\right|_{G_{k}=0}\right]}{G_{k}^{\max }\left[1-\left(\frac{r}{r+t}\right)^{\sigma-1}\left(\frac{r}{r+t}\right)^{\sigma-1}\right]}<0 .
$$

(Use $w^{k}=\frac{C\left(1 / x_{k}^{k}\right)^{\tilde{B}}}{\bar{L}}$ with $C=(1-\alpha) \bar{L}^{1-\alpha} A^{\alpha / \rho}$ and $\left.\widetilde{B}=\alpha\left(\frac{B}{\rho}-1\right).\right)$ Remember the fact that there are only two candidates for an optimal infrastructure policy in country $k$, namely $G_{k}=0$ and $G_{k}=G_{k}^{\max }$. Then, straightforward calculations lead from (13), (14) and (A.24) to Proposition 4.

\section{References}

Arndt, S.W., 1997, Globalization and the Open Economy, North American Journal of Economics and Finance 8, 71-79.

Baldwin, R.E., 2001, The Implications of Increasing Fragmentation and Globalization for the World Trade Organization, in L.K. Cheng and H. Kierzkowski, eds., Global Production and Trade in East Asia, Kluwer Academic Publishers, Boston, 249-271. 
Baldwin, R.E. and P.R. Krugman, 2002, Agglomeration, Integration and Tax Harmonization, NBER Working Paper 9290.

Brakman S., H. Garretsen, and C. van Marrewijk, 2002, Locational Competition and Agglomeration: The Role of Public Spending, CCSO Working Paper 200209.

Breuss, F., P. Egger and M. Pfaffermayr, 2001, The impact of Agenda 2000's structural policy reform on FDI in the EU, Journal of Policy Modeling 23, 807-820.

Burda, M.C. and B. Dluhosch, 2001, Fragmentation, Globalization and Labor Markets, in D. Greenaway, R. Upward and K. Wakelin, eds., Proceedings of IEA Conference on Globalisation and Labour Markets, Macmillan, forthcoming.

Burda, M.C. and B. Dluhosch, 2002, Cost Competition, Fragmentation and Globalization, Review of International Economics 10, 424-41.

Bougheas, S., P.O. Demetriades and E.L. Morgenroth, Infrastructure, 1999, Transport Costs and Trade, Journal of International Economics 47, 169-189.

Bougheas S., P.O. Demetriades and T.P. Mamuneas, 2000, Infrastructure, Specialization, and Economic Growth, Canadian Journal of Economics 33, 506-522.

Deardorff, A.V., 2001, Fragmentation in Simple Trade Models, North American Journal of Economics and Finance 12, 121-137.

Dutch Ministry of Economic Affairs, 1999, Nota Ruimtelijk Economisch Beleid (Report of Location Policy), The Hague.

Egger, H., 2002, International Outsourcing in a Two-Sector Heckscher-Ohlin Model, Journal of Economic Integration 17, 687-709.

Egger, H., and J. Falkinger, 2002, Characterization of the Distributional Effects of International Outsourcing in the Heckscher-Ohlin Model, revised version of the CESifo Working Paper 573. 
Ethier, W.J., 1982, National and International Returns to Scale in the Modern Theory of International Trade, American-Economic-Review 72, 389-405

Feenstra, R.C., 1998, Integration of trade and disintegration of production in the global economy, Journal of Economic Perspectives 12, 3-50.

Feenstra, R.C. and G. Hanson, 1996, Foreign Investment, Outsourcing, and Relative Wages, in: R. Feenstra, G.M. Grossman., and D.A. Irwin, eds., Political Economy of Trade Policy: Essays in Honor of Jagdish Bhagwati (MIT Press, Cambridge, Mass.).

Feenstra, R.C. and G.H. Hanson, 2001, Global Production Sharing and Rising Inequality: A Survey of Trade and Wages, NBER Working Paper 8372, forthcoming in K. Choi and J. Harrigan, eds., Handbook of International Trade, Basil Blackwell, Malden.

Grossman G.M. and E. Helpman, 2002a, Outsourcing versus FDI in Industry Equilibrium, NBER Working Paper 9300.

Grossman G.M. and E. Helpman, 2002b, Managerial Incentives and the International Organization of Production, NBER Working Paper 9403.

Holtz-Eakin, D. and M.E. Lovely, 1996, Scale Economies, Returns to Variety, and the Productivity of Public Infrastructure, Regional Science and Urban Economics 26, 105-123.

Hummels, D. J. Ishii and K.-M. Yi, 2001, The Nature and Growth of Vertical Specialization in World Trade, Journal of International Economics 54, 75-96.

Jones, R.W., 2000, Globalization and the Theory of Input Trade, MIT Press, Cambridge.

Jones, R.W. and H. Kierzkowski, 2001, A Framework for Fragmentation, in S.W. Arndt and H. Kierzkowski, eds., Fragmentation: New Production Patterns in the World Economy, Oxford University Press, Oxford, 17-34. 
Kohler, W., 2001, A Specific Factors View on Outsourcing, North American Journal of Economics and Finance 12, 31-53.

Krugman, P.R., 1991, Increasing Returns and Economic Geography, Journal of Political Economy 99, 483-499.

Krugman, P.R., and A.J. Venables, 1995, Globalization and the Inequality of Nations, Quarterly Journal of Economics 110, 857-80.

Lloyd, P.J., 2001, Rules of Origin and Fragmentation of Trade, in L.K. Cheng and H. Kierzkowski, eds., Global Production and Trade in East Asia, Kluwer Academic Publishers, Boston, 273-287.

Ludema, R.D. and I. Wooton, 2000, Economic geography and the fiscal effects of regional integration, Journal of International Economics 52, 331-357.

Markusen, J.R., 2002, Multinational Firms and the Theory of International Trade, MIT Press, Cambridge.

Markusen, J.R., and A.J. Venables, 2000, The Theory of Endowment, Intra-Industry and Multinational Trade, Journal of International Economics 52, 209-234.

Portland Development Commission, 2002, Location Factors, Appendix 2-3 of the Summary Report: Economic Development Strategy for the City of Portland. 


\section{CESifo Working Paper Series}

(for full list see www.cesifo.de)

903 Mika Widgrén, Enlargements and the Principles of Designing EU - Decision-Making Procedures, April 2003

904 Phornchanok Cumperayot, Dusting off the Perception of Risk and Returns in FOREX Markets, April 2003

905 Kai A Konrad, Inverse Campaigning, April 2003

906 Lars P. Feld and Stefan Voigt, Economic Growth and Judicial Independence: Cross Country Evidence Using a New Set of Indicators, April 2003

907 Giuseppe Bertola and Pietro Garibaldi, The Structure and History of Italian Unemployment, April 2003

908 Robert A.J. Dur and Otto H. Swank, Producing and Manipulating Information, April 2003

909 Christian Gollier, Collective Risk-Taking Decisions with Heterogeneous Beliefs, April 2003

910 Alexander F Wagner, Mathias Dufour, and Friedrich Schneider, Satisfaction not Guaranteed - Institutions and Satisfaction with Democracy in Western Europe, April 2003

911 Ngo Van Long, Raymond Riezman, and Antoine Soubeyran, Trade, Wage Gaps, and Specific Human Capital Accumulation, April 2003

912 Andrea Goldstein, Privatization in Italy 1993-2002: Goals, Institutions, Outcomes, and Outstanding Issues, April 2003

913 Rajshri Jayaraman and Mandar Oak, The Signaling Role of Municipal Currencies in Local Development, April 2003

914 Volker Grossmann, Managerial Job Assignment and Imperfect Competition in Asymmetric Equilibrium, April 2003

915 Christian Gollier and Richard Zeckhauser, Collective Investment Decision Making with Heterogeneous Time Preferences, April 2003

916 Thomas Moutos and William Scarth, Some Macroeconomic Consequences of Basic Income and Employment Subsidies, April 2003

917 Jan C. van Ours, Has the Dutch Miracle Come to an End?, April 2003 
918 Bertil Holmlund, The Rise and Fall of Swedish Unemployment, April 2003

919 Bernd Huber and Marco Runkel, Optimal Design of Intergovernmental Grants under Asymmetric Information, April 2003

920 Klaus Wälde, Endogenous Business Cycles and Growth, April 2003

921 Ramon Castillo and Stergios Skaperdas, All in the Family or Public? Law and Appropriative Costs as Determinants of Ownership Structure, April 2003

922 Peter Fredriksson and Bertil Holmlund, Improving Incentives in Unemployment Insurance: A Review of Recent Research, April 2003

923 Bernard M.S. van Praag and Adam S. Booij, Risk Aversion and the Subjective Time Discount Rate: A Joint Approach, April 2003

924 Yin-Wong Cheung, Kon S. Lai, and Michael Bergman, Dissecting the PPP Puzzle: The Unconventional Roles of Nominal Exchange Rate and Price Adjustment, April 2003

925 Ugo Trivellato and Anna Giraldo, Assessing the 'Choosiness' of Job Seekers. An Exploratory Approach and Evidence for Italy, April 2003

926 Rudi Dornbusch and Stanley Fischer, International Financial Crises, April 2003

927 David-Jan Jansen and Jakob de Haan, Statements of ECB Officials and their Effect on the Level and Volatility of the Euro-Dollar Exchange Rate, April 2003

928 Mario Jametti and Thomas von Ungern-Sternberg, Assessing the Efficiency of an Insurance Provider - A Measurement Error Approach, April 2003

929 Paolo M. Panteghini and Guttorm Schjelderup, Competing for Foreign Direct Investments: A Real Options Approach, April 2003

930 Ansgar Belke, Rainer Fehn, and Neil Foster, Does Venture Capital Investment Spur Employment Growth?, April 2003

931 Assar Lindbeck, Sten Nyberg, and Jörgen W. Weibull, Social Norms and Welfare State Dynamics, April 2003

932 Myrna Wooders and Ben Zissimos, Hotelling Tax Competition, April 2003

933 Torben M. Andersen, From Excess to Shortage - Recent Developments in the Danish Labour Market, April 2003

934 Paolo M. Panteghini and Carlo Scarpa, Irreversible Investments and Regulatory Risk, April 2003

935 Henrik Jacobsen Kleven and Claus Thustrup Kreiner, The Marginal Cost of Public Funds in OECD Countries. Hours of Work Versus Labor Force Participation, April 2003 
936 Klaus Adam, George W. Evans, and Seppo Honkapohja, Are Stationary Hyperinflation Paths Learnable?, April 2003

937 Ulrich Hange, Education Policy and Mobility: Some Basic Results, May 2003

938 Sören Blomquist and Vidar Christiansen, Is there a Case for Public Provision of Private Goods if Preferences are Heterogeneous? An Example with Day Care, May 2003

939 Hendrik Jürges, Kerstin Schneider, and Felix Büchel, The Effect of Central Exit Examinations on Student Achievement: Quasi-experimental Evidence from TIMSS Germany, May 2003

940 Samuel Bentolila and Juan F. Jimeno, Spanish Unemployment: The End of the Wild Ride?, May 2003

941 Thorsten Bayindir-Upmann and Anke Gerber, The Kalai-Smorodinsky Solution in Labor-Market Negotiations, May 2003

942 Ronnie Schöb, Workfare and Trade Unions: Labor Market Repercussions of Welfare Reform, May 2003

943 Marko Köthenbürger, Tax Competition in a Fiscal Union with Decentralized Leadership, May 2003

944 Albert Banal-Estañol, Inés Macho-Stadler, and Jo Seldeslachts, Mergers, Investment Decisions and Internal Organisation, May 2003

945 Kaniska Dam and David Pérez-Castrillo, The Principal-Agent Matching Market, May 2003

946 Ronnie Schöb, The Double Dividend Hypothesis of Environmental Taxes: A Survey, May 2003

947 Erkki Koskela and Mikko Puhakka, Stabilizing Competitive Cycles with Distortionary Taxation, May 2003

948 Steffen Huck and Kai A. Konrad, Strategic Trade Policy and Merger Profitability, May 2003

949 Frederick van der Ploeg, Beyond the Dogma of the Fixed Book Price Agreement, May 2003

950 Thomas Eichner and Rüdiger Pethig, A Microfoundation of Predator-Prey Dynamics, May 2003

951 Burkhard Heer and Bernd Süssmuth, Cold Progression and its Effects on Income Distribution, May 2003

952 Yu-Fu Chen and Michael Funke, Labour Demand in Germany: An Assessment of NonWage Labour Costs, May 2003 
953 Hans Gersbach and Hans Haller, Competitive Markets, Collective Decisions and Group Formation, May 2003

954 Armin Falk, Urs Fischbacher, and Simon Gächter, Living in Two Neighborhoods Social Interactions in the LAB, May 2003

955 Margarita Katsimi, Training, Job Security and Incentive Wages, May 2003

956 Clemens Fuest, Bernd Huber, and Jack Mintz, Capital Mobility and Tax Competition: A Survey, May 2003

957 Edward Castronova, The Price of 'Man' and 'Woman': A Hedonic Pricing Model of Avatar Attributes in a Synthetic World, June 2003

958 Laura Bottazzi and Marco Da Rin, Financing Entrepreneurial Firms in Europe: Facts, Issues, and Research Agenda, June 2003

959 Bruno S. Frey and Matthias Benz, Being Independent is a Great Thing: Subjective Evaluations of Self-Employment and Hierarchy, June 2003

960 Aaron Tornell and Frank Westermann, Credit Market Imperfections in Middle Income Countries, June 2003

961 Hans-Werner Sinn and Wolfgang Ochel, Social Union, Convergence and Migration, June 2003

962 Michael P. Devereux, Measuring Taxes on Income from Capital, June 2003

963 Jakob de Haan, Jan-Egbert Sturm and Bjørn Volkerink, How to Measure the Tax Burden on Labour at the Macro-Level?, June 2003

964 Harry Grubert, The Tax Burden on Cross-Border Investment: Company Strategies and Country Responses, June 2003

965 Kirk A. Collins and James B. Davies, Measuring Effective Tax Rates on Human Capital: Methodology and an Application to Canada, June 2003

966 W. Steven Clark, Using Micro-Data to Assess Average Tax Rates, June 2003

967 Christopher Heady, The 'Taxing Wages' Approach to Measuring the Tax Burden on Labour, June 2003

968 Michael P. Devereux and Alexander Klemm, Measuring Taxes on Income from Capital: Evidence from the UK, June 2003

969 Bernhard Eckwert and Itzhak Zilcha, The Effect of Better Information on Income Inequality, June 2003

970 Hartmut Egger and Josef Falkinger, The Role of Public Infrastructure for Firm Location and International Outsourcing, June 2003 